\title{
Myricetin induces apoptosis via endoplasmic reticulum stress and DNA double-strand breaks in human ovarian cancer cells
}

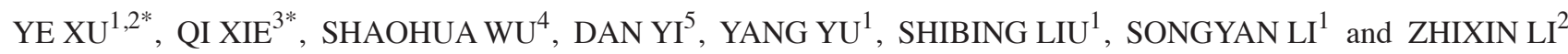 \\ ${ }^{1}$ Medical Research Laboratory; ${ }^{2}$ Department of Histology and Embryology, Jilin Medical University, Jilin, Jilin 132013; \\ ${ }^{3}$ Department of Pathophysiology, Basic Medical College, Jilin University, Changchun, Jilin 130021; \\ ${ }^{4}$ Department of Medical Laboratory, Jilin Medical University, Jilin, Jilin 132013; ${ }^{5}$ Medical Examination Center, \\ Jilin Traditional Chinese and Western Medicine Hospital, Jilin, Jilin 132010, P.R. China
}

Received February 3, 2015; Accepted December 8, 2015

DOI: $10.3892 / \mathrm{mmr} .2016 .4763$

\begin{abstract}
The mechanisms underlying myricetin-induced cancer cell apoptosis remain to be elucidated. Certain previous studies have shown that myricetin induces apoptosis through the mitochondrial pathway. Apoptosis, however, can also be induced by other classical pathways, including endoplasmic reticulum (ER) stress and DNA double-strand breaks (DSBs). The aim of the present study was to assess whether these two apoptotic pathways are involved in myricetin-induced cell death in SKOV3 ovarian cancer cells. The results revealed that treatment with myricetin inhibited viability of SKOV3 cells in a dose-dependent manner. Myricetin induced nuclear chromatin condensation and fragmentation, and also upregulated the protein levels of active caspase 3 in a time-dependent manner. In addition, myricetin upregulated ER stress-associated proteins, glucose-regulated protein-78 and $\mathrm{C} / \mathrm{EBP}$ homologous protein in SKOV3 cells. Phosphorylation of $\mathrm{H}_{2} \mathrm{AX}$, a marker of DNA DSBs, was revealed to be upregulated in myricetin-treated cells. The data indicated that myricetin induces DNA DSBs and ER stress, which leads to apoptosis in SKOV3 cells.
\end{abstract}

\section{Introduction}

Ovarian cancer is one of the most common gynecological malignancies and the seventh most common type of cancer in women. More than 14,000 women succumb to ovarian cancer annually and there appears to be a global increase in the incidence rates (1-3). The clinical application of chemotherapeutic drugs to treat ovarian cancer is extended, however, the side

Correspondence to: Professor Zhixin Li, Department of Histology and Embryology, Jilin Medical University, 5 Jilin Street, Jilin, Jilin 132013, P.R. China

E-mail:1zx-62@163.com

${ }^{*}$ Contributed equally

Key words: myricetin, apoptosis, endoplasmic reticulum stress, DNA double-strand breaks, ovarian cancer effects of these drugs limit their usefulness $(4,5)$. It is therefore essential that novel drugs are developed for the treatment of ovarian cancer.

Flavonoids are composed of $>4,000$ polyphenolic compounds present in vegetables, fruits, tea and certain medicinal herbs $(6,7)$. Flavonoids are divided into flavones, flavanonols, flavanols, isoflavones and flavonols, according to their saturation levels $(8,9)$. Myricetin $(2,5,7,3,4,5$-pentahydroxylflavonol) is a ubiquitous flavonol (10). Previous studies have shown that myricetin is effective against certain types of cancer (11-13), however, its mechanisms of action in human ovarian cancer remain to be elucidated. The present study examined the effects of myricetin on SKOV3 ovarian cancer cells and explored the apoptotic pathways involved in myricetin-induced SKOV3 cell death.

The endoplasmic reticulum (ER) is an organelle with various important biological functions in eukaryotic cells. Several physiological and pathological factors can trigger ER stress. Glucose-regulated protein (GRP)-78, an ER stress chaperone molecule, is upregulated when various stimuli trigger ER stress. Moderate ER stress can act as a protective mechanism (14), however, prolonged and excessive ER stress eventually leads to apoptosis $(14,15)$. Previous studies have suggested that DNA doubled-strand breaks (DSBs) can also lead to apoptosis (16-18). Phosphorylation of $\mathrm{H}_{2} \mathrm{AX}\left(\gamma-\mathrm{H}_{2} \mathrm{AX}\right)$ is a widely recognized marker of DNA DSBs, and increases in DNA DSBs are reflected by the upregulation of $\gamma-\mathrm{H}_{2} \mathrm{AX}$ levels (17).

In the present study, myricetin treatment inhibited SKOV 3 cell viability and induced subsequent apoptosis. The present study identified both ER stress and DNA DSBs as factors involved in myricetin-induced SKOV3 cell apoptosis.

\section{Materials and methods}

Cell culture and treatment. Human ovarian cancer SKOV3 cells were purchased from the Chinese Academy of Medical Sciences (Beijing, China) and were maintained in RPMI-1640 (Gibco; Thermo Fisher Scientific, Inc., Carlsbad, CA, USA), supplemented with $10 \%(\mathrm{v} / \mathrm{v})$ fetal calf serum (Gibco; Thermo Fisher Scientific, Inc.), $100 \mathrm{mg} / \mathrm{ml}$ streptomycin and $100 \mathrm{U} / \mathrm{ml}$ penicillin (each from Genview, 
Galveston, TX, USA). The cells were incubated at $37^{\circ} \mathrm{C}$ in an atmosphere containing $5 \% \mathrm{CO}_{2}$. Myricetin was purchased from Sigma-Aldrich (St. Louis, MO, USA) and was dissolved in dimethylsulfoxide (DMSO) for storage at $-20^{\circ} \mathrm{C}$.

Cell viability assay. Cell viability was determined using a 3-(4,5-dimetrylthiazol-2-yl)-2,5-diphenyltetrazolium bromide (MTT) assay (Beyotime Institute of Biotechnology, Haimen, China). SKOV3 cells, during the exponential growth phase, were seeded into 96-well culture plates in $100 \mu \mathrm{l}$ RPMI-1640 at a density of $8 \times 10^{3}$ cells/well. Following $24 \mathrm{~h}$ incubation, the indicated dose of myricetin were added for a further $24 \mathrm{~h}$ incubation in four parallel wells. The MTT assays were performed as follows: $20 \mu \mathrm{l}$ MTT solution $[(5 \mathrm{mg} / \mathrm{ml}$ in phosphate-buffered saline (PBS)] was added to each well and the cells were incubated at $37^{\circ} \mathrm{C}$ for $4 \mathrm{~h}$, following which $150 \mu \mathrm{l}$ DMSO (Beijing Chemical Industry Co., Ltd., Beijing, China) was added to each well. The cells were agitated for $10 \mathrm{~min}$ prior to measuring the absorbance at $570 \mathrm{~nm}$ using a microplate reader (680; Bio-Rad Laboratories, Inc., Hercules, CA, USA). The growth inhibition rate was calculated as follows: Inhibition $(\%)=[1$ - (absorbance of experimental group / absorbance of control group)] x 100 . The mean value of four replicate wells was calculated for each treatment group.

Western blotting. Whole-cell protein extracts from SKOV3 cells were prepared using cell lysis buffer [50 mM Tris-hydrochloride ( $\mathrm{HCl} ; \mathrm{pH} 7.5) ; 150 \mathrm{mM} \mathrm{NaCl} ; 1 \mathrm{mM}$ $\mathrm{Na}_{2}$ EDTA; $1 \mathrm{mM}$ EDTA; $1 \%$ Triton; $2.5 \mathrm{mM}$ sodium pyrophosphate; $1 \mathrm{mM} \beta$-glycerophosphate; $1 \mathrm{mM} \mathrm{Na} \mathrm{VO}_{4} ; 1 \mathrm{mM}$ $\mathrm{NaF} ; 1 \mu \mathrm{g} / \mathrm{ml}$ leupeptin; $1 \mathrm{mM}$ PMSF]. The protein extracts were quantified using a Bio-Rad Protein Assay kit (Bio-Rad Laboratories, Inc.). For western blot analysis, protein lysates $(30-50 \mu \mathrm{g})$ were separated by $12 \%$ sodium dodecyl sulfate-polyacrylamide gel electrophoresis and transferred onto Immobilon-P Membranes (EMD Millipore, Billerica, MA, USA). The membranes were blocked with 5\% non-fat milk powder in buffer [10 mM Tris- $\mathrm{HCl}$ (pH 7.6), $100 \mathrm{mM}$ $\mathrm{NaCl}$ and $0.1 \%$ Tween-20] for $2 \mathrm{~h}$ at room temperature and were subsequently incubated with the appropriate primary antibodies overnight at $4^{\circ} \mathrm{C}$. Anti-GRP-78 rabbit anti-human polyclonal antibody (cat no. sc-13968; dilution, 1:200) was obtained from Santa Cruz Biotechnology, Inc. (Santa Cruz, CA, USA), mouse anti-human anti-C/EBP homologous protein (CHOP) monoclonal antibody (cat no. ab11419; dilution, 1:1,000) from Abcam (Hong Kong, China), rabbit anti-human anti- $\gamma-\mathrm{H}_{2} \mathrm{AX}$ monoclonal antibody (cat no. 9718; dilution, 1:1,000) from Cell Signaling Technology (Beverly, MA, USA), and mouse anti-human anti- $\beta$-actin monoclonal antibody (cat no. 60008-1-Ig; dilution, 1:1,000) from Proteintech Group, Inc. (Chicago, IL, USA). Following incubation, the membranes were incubated with horseradish peroxidase-conjugated secondary antibody (Thermo Fisher Scientific, Inc.) at a dilution of 1:2,000 for $1 \mathrm{~h}$ at room temperature. Immunodetection was performed using enhanced chemiluminescence reagents and images were captured using a Syngene Bio Imaging system (Synoptics, Cambridge, UK). The protein levels were normalized against those of $\beta$-actin, and the ratios of the normalized protein are presented as the mean \pm standard deviation from three independent experiments. Protein levels were quantified by densitometry using Quantity One software version 4.4.02 (Bio-Rad Laboratories, Inc.).

Immunofluorescent staining and confocal laser microscopy. The cells were seeded onto coverslips in 24-well plates at a density of $5 \times 10^{4}$ cells/well $24 \mathrm{~h}$ prior to treatment. Following exposure to $40 \mu \mathrm{g} / \mathrm{ml}$ myricetin for $0,6,12$ and $24 \mathrm{~h}$, the cells were fixed with $4 \%$ paraformaldehyde for $30 \mathrm{~min}$ at room temperature, stained with the nuclear stain Hoechst 33342 ( $2 \mu \mathrm{g} / \mathrm{ml}$; Sigma-Aldrich) for $2 \mathrm{~min}$ at room temperature, washed with PBS and examined using a confocal laser microscope (FV1000; Olympus, Tokyo, Japan) to reveal chromatin condensation. The expression levels of GRP-78, active Caspase 3 and $\gamma-\mathrm{H}_{2} \mathrm{AX}$ were examined using an indirect immunofluorescence method. Briefly, after the cells were cultured, treated and fixed, as previously described, they were subsequently permeabilized with $0.1 \%$ Triton X-100 for $5 \mathrm{~min}$, blocked with bovine serum albumin for $30 \mathrm{~min}$ and incubated with primary antibodies against GRP-78, active caspase 3 and $\gamma-\mathrm{H}_{2} \mathrm{AX}$ (dilution, 1:100) overnight at $4{ }^{\circ} \mathrm{C}$. Following incubation, the cells were incubated with fluorescein isothiocyanate/Texas Red-conjugated secondary antibodies (dilution, 1:400; Santa Cruz Biotechnology, Inc.) for $1 \mathrm{~h}$ at room temperature, stained with Hoechst $33342(2 \mu \mathrm{g} / \mathrm{ml})$ for $2 \mathrm{~min}$ at room temperature, washed with PBS three times, and examined using the Olympus FV1000 confocal laser microscope.

Statistical analysis. The data are representative of the results from three independent experiments. Statistical analysis was performed using one-way analysis of variance. The Tukey post-hoc test was used to determine the significance of all pairwise comparisons of interest. $\mathrm{P}<0.05$ was considered to indicate a statistically significant difference.

\section{Results}

Myricetin inhibits the viability of SKOV3 cells. Our previous results provided us with the appropriate dose range for myricetin treatment (unpublished data). SKOV3 cells were treated with the indicated doses of myricetin for $24 \mathrm{~h}$. Myricetin inhibited the viability of SKOV3 cells in a dose-dependent manner (Fig. 1A). In addition, changes in cell morphology were also apparent following myricetin treatment. Myricetin-treated cells appeared more rounded and shrunken compared with the control group (Fig. 1B). The present study, therefore, hypothesized that myricetin may induce apoptosis in SKOV3 cells, and this was examined in detail using confocal microscopy.

Myricetin triggers apoptosis in SKOV3 cells. Based on the above MTT results, SKOV3 cells were treated with $40 \mu \mathrm{g} / \mathrm{ml}$ myricetin for $0,6,12$ or $24 \mathrm{~h}$, stained with Hoechst 33342, and examined using confocal microscopy. The nuclei of myricetin-treated cells appeared more condensed, when compared with the untreated cells (Fig. 2A).

Caspase 3 is considered to be the primary executor of apoptosis, and cleaved Caspase 3 (active Caspase 3) is used as a biomarker for apoptosis. As shown in Fig. 2B, increasing concentrations of myricetin generated higher levels of red fluorescence. This indicated that myricetin induced the activation 
$\mathbf{A}$

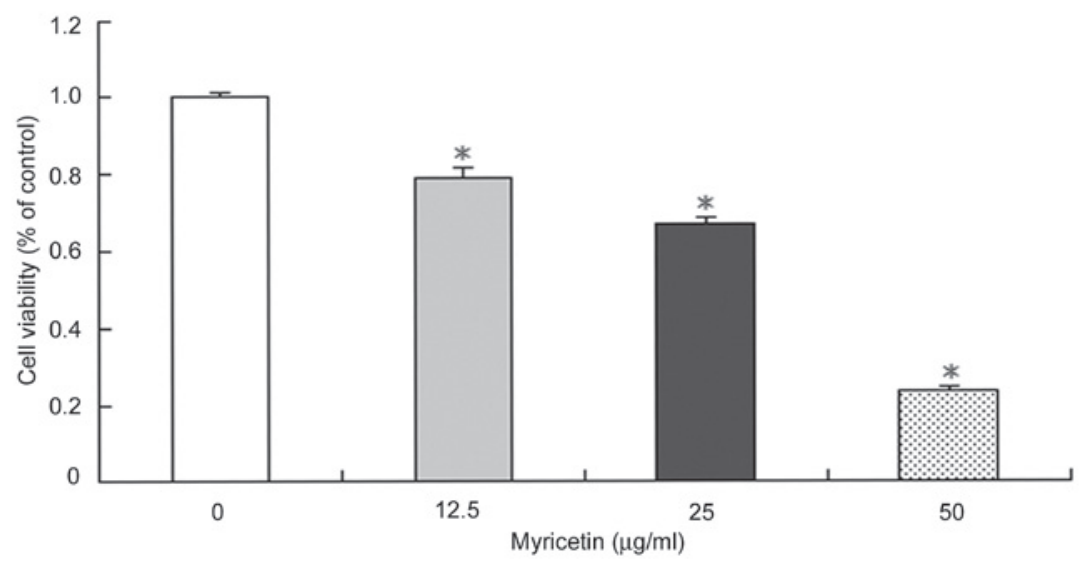

$\mathbf{B}$

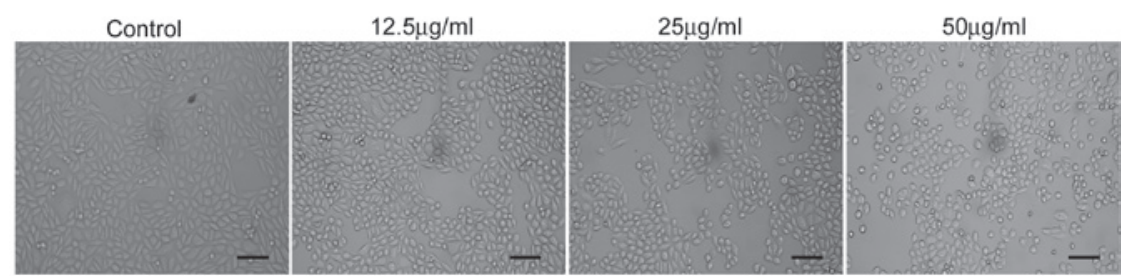

Figure 1. Myricetin inhibits the viability of SKOV3 cells. SKOV3 cells were treated with different doses of myricetin for $24 \mathrm{~h}$. (A) Cell viability was measured by a 3-(4,5-dimetrylthiazol-2-yl)-2,5-diphenyltetrazolium bromide assay and decreased in a dose-dependent manner. (B) Images were captured using an inverted phase contrast microscope at a magnification of $\mathrm{x} 100$ (scale bar, $50 \mu \mathrm{m}$ ). Data are expressed as the mean \pm standard deviation $\left(\mathrm{n}=3\right.$; ${ }^{*} \mathrm{P}<0.05$, vs. control).

A
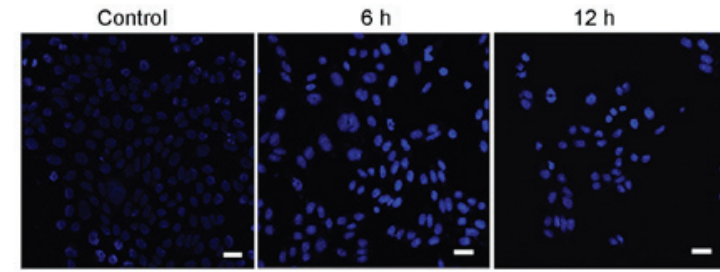

$24 \mathrm{~h}$

B

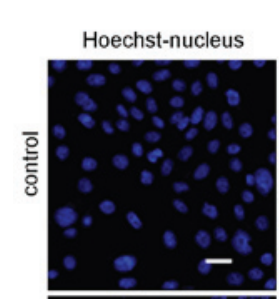

Alexa Fluor546
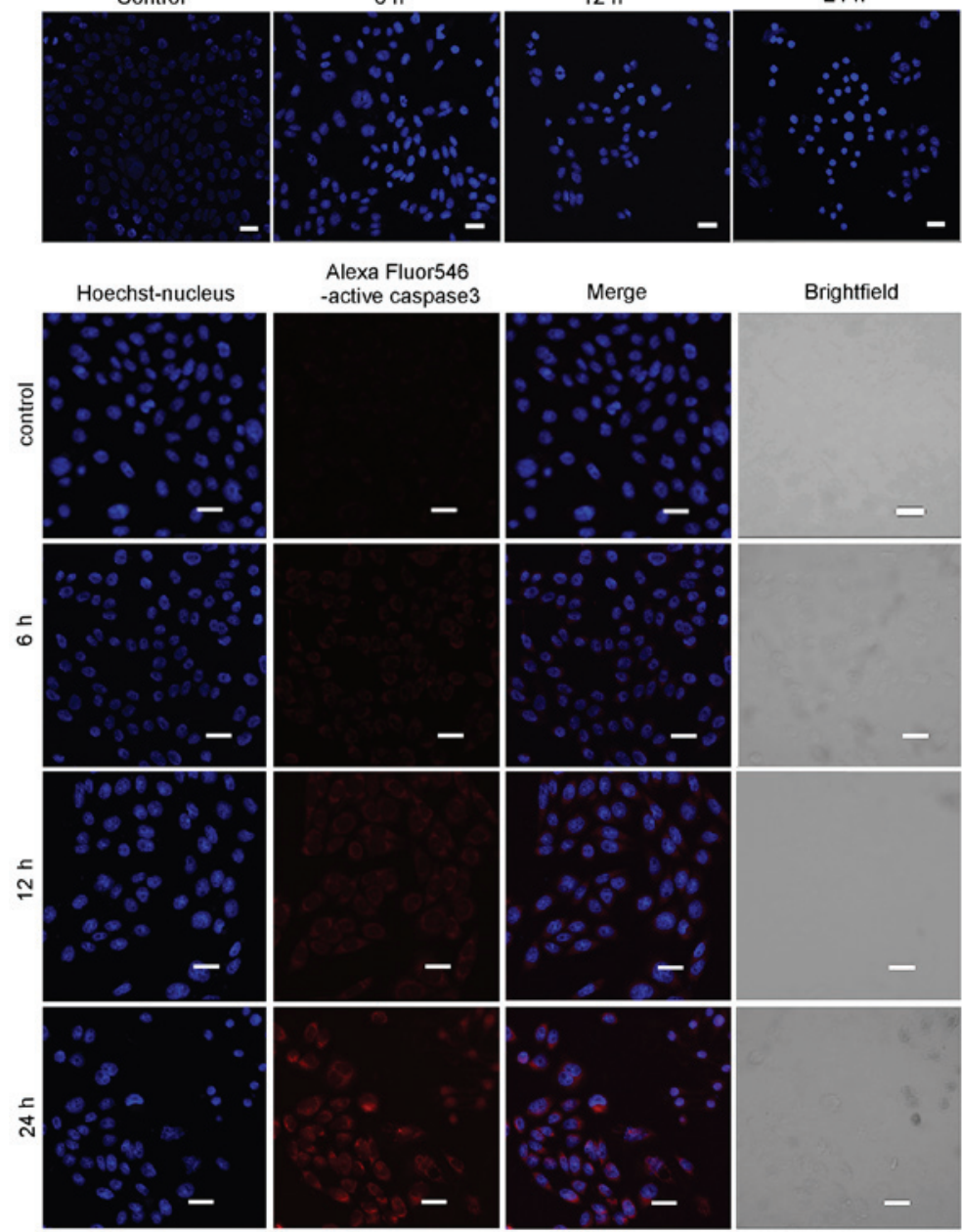

Figure 2. Myricetin induces apoptosis in SKOV3 cells. (A) The cells were treated with $40 \mu \mathrm{g} / \mathrm{ml}$ myricetin for $0,6,12$ and $24 \mathrm{~h}$, and were subsequently stained with Hoechst 33342. Confocal microscopy was used to observe cell morphology (scale bar, $20 \mathrm{~mm}$ ). (B) The cells were treated with $40 \mu \mathrm{g} / \mathrm{ml} \mathrm{myricetin}$ for 0, 6, 12 and $24 \mathrm{~h}$. Nuclear staining and fluorescence of active Caspase 3 was observed using confocal microscopy (scale bar, $20 \mu \mathrm{m}$ ). 
A

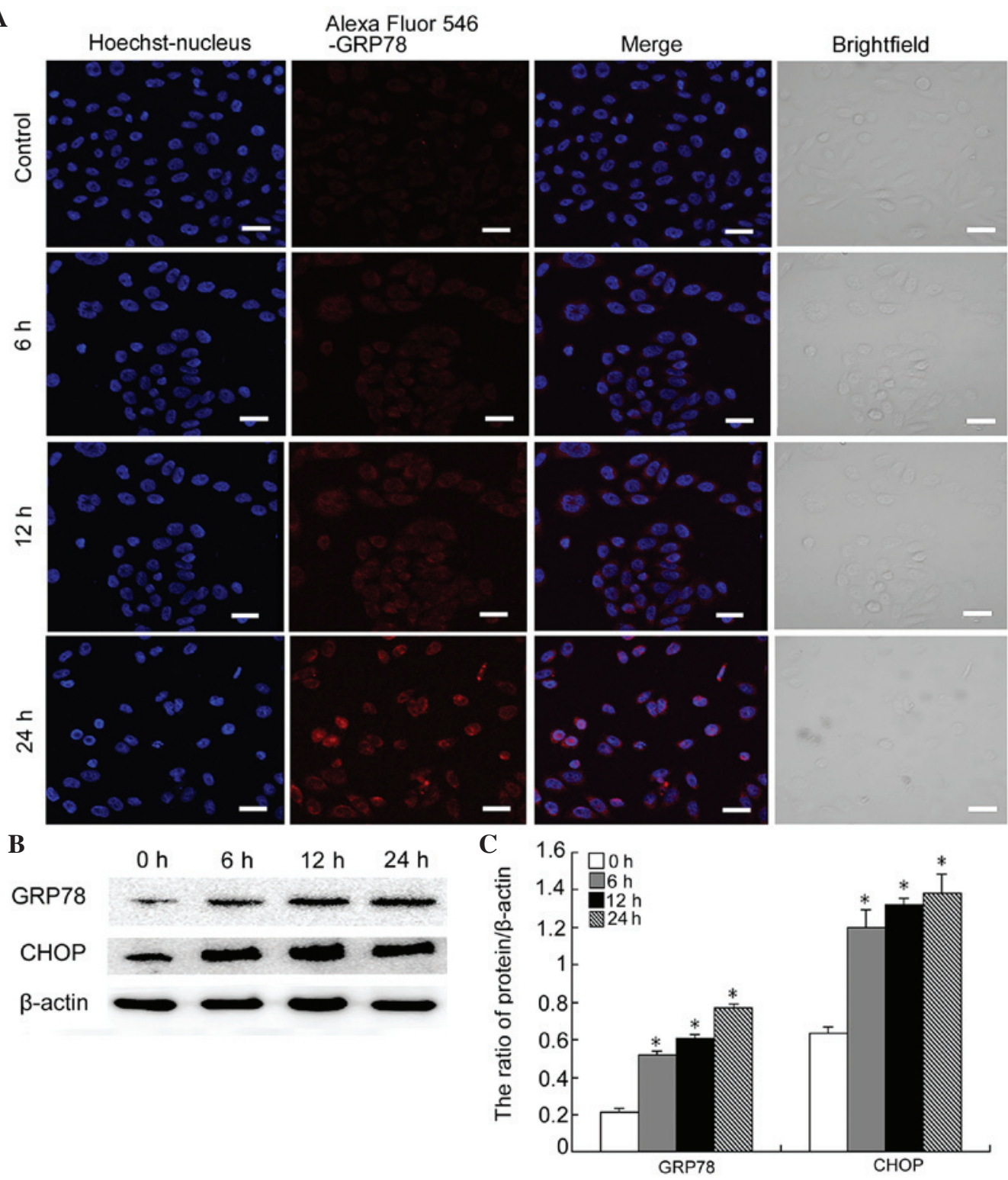

Figure 3. Myricetin induces ER stress-associated apoptosis in SKOV3 cells. (A) The cells were treated with $40 \mu \mathrm{g} / \mathrm{ml}$ myricetin for 0, 6, 12 and $24 \mathrm{~h}$. The expression of GRP-78 was detected using confocal microscopy (scale bar, $20 \mu \mathrm{m}$ ). (B) Western blot analysis was performed to determine the expression levels of GRP-78 and CHOP in SKOV3 cells following treatment with $40 \mu \mathrm{g} / \mathrm{ml}$ myricetin for 0, 6, 12 and $24 \mathrm{~h}$. (C) Quantification of the protein expression levels of GRP-78 and CHOP. The data were normalized against $\beta$-actin and are expressed as the mean \pm standard deviation $(\mathrm{n}=3$; " $\mathrm{P}<0.05$, vs. control). GRP, glucose-regulated protein; $\mathrm{CHOP}, \mathrm{C} / \mathrm{EBP}$ homologous protein.

of Caspase 3 in a time-dependent manner (Fig. 2b). Together, these results indicated that myricetin triggered apoptosis in SKOV3 cells.

Myricetin induces ER stress-associated apoptosis in SKOV3 cells. GRP-78 is an ER chaperone molecule, which increases following ER stress (19). In order to determine whether myricetin induced ER stress, confocal microscopy was used to detect the expression of GRP-78 in myricetin-treated cells. Myricetin was found to increase the mean fluorescence intensity of GRP-78 in SKOV3 cells, which became notable following $24 \mathrm{~h}$ of treatment (Fig. 3A).

Increased and sustained ER stress can cause an apoptotic response. To determine whether the response to myricetin treatment caused ER stress-associated apoptosis, the levels of CHOP were investigated (20). Western blot analysis indicated that the protein levels of CHOP markedly increased at 6,12 and $24 \mathrm{~h}$ following myricetin treatment (Fig. 3B and $\mathrm{C}$ ). Consistent with the data from the confocal experiments, GRP-78 levels also increased in a time-dependent manner (Fig. 2B and C). These results indicated that myricetin triggers ER stress-associated apoptosis.

Myricetin induces DNA DSBs in SKOV3 cells. Cisplatin is one of the classic chemotherapeutic drugs known to induce a marked apoptotic response by inhibiting DNA replication and damage $(21,22)$. It was therefore hypothesized that myricetin can also induce DNA DSBs. It has been reported that following a DSB, histone $\mathrm{H}_{2} \mathrm{AX}$ is rapidly phosphorylated (becoming $\left.\gamma-\mathrm{H}_{2} \mathrm{AX}\right)$ near the site of the DSB, and is involved in the recruitment of other factors that contribute to lesion repair. The levels of $\gamma-\mathrm{H}_{2} \mathrm{AX}$ have been shown to be downregulated 


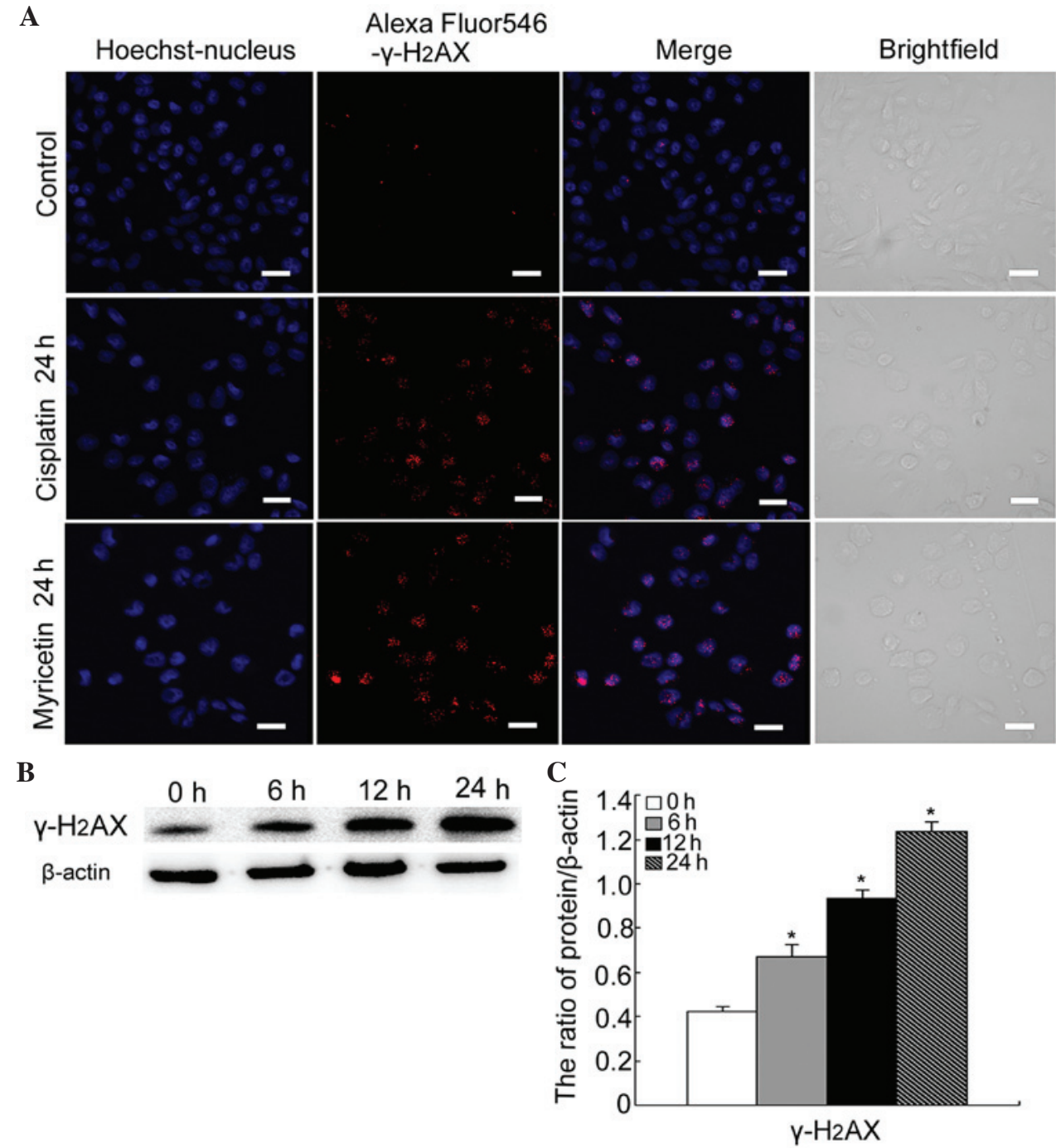

Figure 4. Myricetin facilitates DNA double-strand breaks in SKOV3 cells. (A) The cells were treated with cisplatin $(6 \mu \mathrm{g} / \mathrm{ml})$ or myricetin $(40 \mu \mathrm{g} / \mathrm{ml})$ for 0 and $24 \mathrm{~h}$. The expression of $\gamma-\mathrm{H}_{2} \mathrm{AX}$ was observed using confocal microscopy (scale bar, $20 \mu \mathrm{m}$ ). (B) Western blot analysis was performed to detect the expression of $\gamma-\mathrm{H}_{2} \mathrm{AX}$ in SKOV3 cells following treatment with $40 \mu \mathrm{g} / \mathrm{ml}$ myricetin for $0,6,12$ and $24 \mathrm{~h}$. (C) Quantification of the protein expression of $\gamma-\mathrm{H}_{2} \mathrm{AX}$. The data were normalized against $\beta$-actin and are expressed as the mean \pm standard deviation $(\mathrm{n}=3)$. ${ }^{\mathrm{P}} \mathrm{P}<0.05$ vs. control.

when the DNA is repaired. If the lesion remains unrepaired (or the repair process is delayed), then the levels of $\gamma-\mathrm{H}_{2} \mathrm{AX}$ remain high; therefore, the levels of $\gamma-\mathrm{H}_{2} \mathrm{AX}$ comprise an ideal indicator of the degree of unrepaired DSBs, which can then contribute to cell death $(23,24)$.

Firstly, using confocal microscopy, the expression of $\gamma-\mathrm{H}_{2} \mathrm{AX}$ was detected in cells treated with either cisplatin $(6 \mu \mathrm{g} / \mathrm{ml})$ or myricetin $(40 \mu \mathrm{g} / \mathrm{ml})$. Cisplatin-treated cells were used as the positive control. The results revealed that both cisplatin and myricetin increased the formation of the $\gamma-\mathrm{H}_{2} \mathrm{AX}$ foci (Fig. 4A). Secondly, western blotting was used to detect the protein levels of $\gamma-\mathrm{H}_{2} \mathrm{AX}$ in myricetin-treated cells. It was revealed that myricetin increased the levels of $\gamma-\mathrm{H}_{2} \mathrm{AX}$ at 6,12 and $24 \mathrm{~h}$ treatment (Fig. 4B and C).

\section{Discussion}

Myricetin is abundant in nature and can be found in walnuts, vegetables and fruits (25). Myricetin has numerous biological functions, including antioxidant and anticarcinogenic functions. In addition, myricetin has been reported to inhibit RNA/DNA replication and repair (26-28). A number of its biological functions suggest its potential use in clinical medicine. In HCT-15 colon cancer cells, myricetin induced cytotoxicity, which was mediated by a mitochondrial pathway (25). A different study indicated that myricetin can be used as auxiliary therapy, increasing the sensitivity of esophageal carcinoma cells to 5-fluorouracil in vitro and in vivo (29). In the present study, myricetin inhibited viability, induced nuclear fragmentation, upregulated the level of active Caspase 3, and subsequently induced apoptosis in SKOV3 cells. Apoptosis can be governed by extrinsic or intrinsic pathways; however, this study focused on the effect of myricetin on the intrinsic pathways, and in particular the ER stress-associated pathway.

ER is an organelle responsible for a number of functions, including the maintenance of intracellular calcium balance and protein synthesis, modification and processing. Numerous cellular pathological and physiological processes can cause ER stress $(30,31)$, which, in turn, can trigger the unfolded 
protein response (UPR) to recover ER homeostasis. UPR signaling pathways include the inositol-requiring enzyme (IRE)1, activating transcription factor (ATF)6 and protein kinase RNA-like endoplasmic reticulum kinase (PERK) pathways. GRP-78, an ER stress molecular chaperone, is upregulated following ER stress, and has a positive regulatory role in the prevention of apoptosis (32); however, severe and persistent ER stress has been reported to induce apoptosis even when GRP-78 protein is overexpressed (33). CHOP is a downstream element of the ER stress pathway and a convergence point of the IRE1, ATF6 and PERK pathways (34). CHOP is known to have a regulatory role as an apoptotic switch. It has been shown that a high expression of CHOP contributes to ER stress-mediated apoptosis. An increasing number of studies have identified ER as a target of apoptosis-inducing drugs in cancer cells (35-37).

The present study demonstrated that myricetin upregulated the level of GRP-78 and CHOP in a time-dependent manner. It further revealed that myricetin induces ER stress-associated apoptosis in SKOV3 cells. Under normal conditions, DSBs occur and are quickly repaired by DNA repair mechanisms. Failure of these mechanisms leads to unrepaired DSBs, ultimately resulting in apoptosis $(38,39)$. The expression of $\gamma-\mathrm{H}_{2} \mathrm{AX}$ comprises a marker for unrepaired DSBs. The present results showed that myricetin induces DNA DSBs in SKOV3 cells, suggesting that myricetin may target DNA damage repair.

In conclusion, myricetin treatment was revealed to inhibit viability and induce apoptosis through ER stress and DNA DSBs in SKOV3 human ovarian cancer cells.

\section{Acknowledgements}

The present study was supported by the National Nature and Science foundation of China (nos. NSFC81372793 and 81272876), the Department of Education of Jilin Province Project (no. 2013361) and the Scientific Research Foundation of Jilin Province for University Students. The authors would like to thank Director Benjamin Shaw from Liwen Bianji (Edanz Group China) for the language editing of this manuscript.

\section{References}

1. Siegel R, Naishadham D and Jemal A: Cancer statistics, 2013. CA Cancer J Clin 63: 11-30, 2013.

2. Tumanian SV and Iartseva DV: Effect of hepatic functional activity of the liver and endogenous intoxication in patients with ovarian cancer. Khirurgiia (Mosk): 45-47, 2014 (In Russian).

3. Shilpa V, Bhagat R, Premalata CS, Pallavi VR, Ramesh G and Krishnamoorthy L: Relationship between promoter methylation \& tissue expression of MGMT gene in ovarian cancer. Indian J Med Res 140: 616-623, 2014.

4. Shibata Y: Initial safety and efficacy of cisplatin and gemcitabine combination chemotherapy for unresectable biliary tract cancer. Gan To Kagaku Ryoho 41: 2599-2602, 2014.

5. Yang J, Shi Y, He X, Dong M, Zhang C, Liu P, Zhou S, Qin Y, Gui L, Yang S and Sun Y: A pilot study of the safety and efficacy of dexamethasone, ifosfamide, methotrexate and gemcitabine chemotherapy for natural killer/T-cell lymphoma. Leuk Lymphoma 56: 2218-2221, 2015.

6. Liu X, Ye F, Wu J, How B, Li W and Zhang DY: Signaling proteins and pathways affected by flavonoids in leukemia cells. Nutr Cancer 67: 238-249, 2015.

7. Schwarz D, Kisselev P, Schunck WH and Roots I: Inhibition of $17 \beta$-estradiol activation by CYP1A1: Genotype- and regioselective inhibition by St. John's Wort and several natural polyphenols. Biochim Biophys Acta 1814: 168-174, 2011.
8. Kozyra M and Skalicka-Woźniak K: Quantitative analysis of flavonoids and phenolic acids from inflorescences and aerial parts of selected Cirsium species using ASE method. Acta Pol Pharm 71: 877-881, 2014.

9. Tsui KC, Chiang TH, Wang JS, Lin LJ, Chao WC, Chen BH and Lu JF: Flavonoids from gynostemma pentaphyllum exhibit differential induction of cell cycle arrest in $\mathrm{H} 460$ and A549 cancer cells. Molecules 19: 17663-17681, 2014.

10. Wu C, Wang W, Tian B, Liu X, Qu X, Zhai Z, Li H, Liu F, Fan Q, Tang T, et al: Myricetin prevents titanium particle-induced osteolysis in vivo and inhibits RANKL-induced osteoclastogenesis in vitro. Biochem Pharmacol 93: 59-71, 2015.

11. Weng CJ and Yen GC: Flavonoids, a ubiquitous dietary phenolic subclass, exert extensive in vitro anti-invasive and in vivo anti-metastatic activities. Cancer Metastasis Rev 31: 323-351, 2012.

12. Sun F, Zheng XY, Ye J, Wu TT, Wang JL and Chen W: Potential anticancer activity of myricetin in human T24 bladder cancer cells both in vitro and in vivo. Nutr Cancer 64: 599-606, 2012.

13. Choi HN, Kang MJ, Lee SJ and Kim JI: Ameliorative effect of myricetin on insulin resistance in mice fed a high-fat, high-sucrose diet. Nutr Res Pract 8: 544-549, 2014.

14. Brüning A, Kimmich T, Brem GJ, Buchholtz ML, Mylonas I, Kost B, Weizsäcker K and Gingelmaier A: Analysis of endoplasmic reticulum stress in placentas of HIV-infected women treated with protease inhibitors. Reprod Toxicol 50: 122-128, 2014.

15. Marí M, Morales A, Colell A, García-Ruiz C and Fernández-Checa JC: Mitochondrial cholesterol accumulation in alcoholic liver disease: Role of ASMase and endoplasmic reticulum stress. Redox Bio 3: 100-108, 2014.

16. Bazyka DA, Muzalevska KD, Maznichenko OL and Belyaev OA: Expression of $\gamma-\mathrm{H} 2 \mathrm{AX}$ histone in lymphocytes of the Chornobyl 'Shelter' object staff exposed to ionizing radiation in occupational limits. Probl Radiac Med Radiobiol 19: 186-191, 2014 (In English, Ukrainian).

17. Valdiglesias V, Giunta S, Fenech M, Neri M and Bonassi S: $\gamma-\mathrm{H} 2 \mathrm{AX}$ as a marker of DNA double strand breaks and genomic instability in human population studies. Mutat Res 753: 24-40, 2013.

18. Reynolds M, Armknecht S, Johnston T and Zhitkovich A: Undetectable role of oxidative DNA damage in cell cycle, cytotoxic and clastogenic effects of $\mathrm{Cr}(\mathrm{VI})$ in human lung cells with restored ascorbate levels. Mutagenesis 27: 437-443, 2012.

19. Fan L, Li A, Li W, Cai P, Yang B, Zhang M, Gu Y, Shu Y, Sun Y, Shen Y, et al: Novel role of Sarco/endoplasmic reticulum calcium ATPase 2 in development of colorectal cancer and its regulation by F36, a curcumin analog. Biomed Pharmacother 68: 1141-1148, 2014.

20. Xu Y, Yu H, Qin H, Kang J, Yu C, Zhong J, Su J, Li H and Sun L: Inhibition of autophagy enhances cisplatin cytotoxicity through endoplasmic reticulum stress in human cervical cancer cells. Cancer Lett 314: 232-243, 2012.

21. Maheshwari RA, Sailor GU, Patel L and Balaraman R: Amelioration of cisplatin-induced nephrotoxicity by statins. Indian J Pharmacol 45: 354-358, 2013.

22. Lingeman RG, Hickey RJ and Malkas LH: Expression of a novel peptide derived from PCNA damages DNA and reverses cisplatin resistance. Cancer Chemother Pharmacol 74: 981-993, 2014.

23. Bazyka DA, Muzalevska KD, Maznichenko OL and Belyaev OA: Expression of $\gamma$-H2AX histone in lymphocytes of the Chornobyl 'Shelter' object staff exposed to ionizing radiation in occupational limits. Probl Radiac Med Radiobiol 19: 186-191, 2014 (In English, Ukrainian).

24. Thompson CM, Seiter J, Chappell MA, Tappero RV, Proctor DM, Suh M, Wolf JC, Haws LC, Vitale R, Mittal L, et al: Synchrotron-based imaging of chromium and $\gamma-\mathrm{H} 2 \mathrm{AX}$ immunostaining in the duodenum following repeated exposure to $\mathrm{Cr}(\mathrm{VI})$ in drinking water. Toxicol Sci 143: 16-25, 2015.

25. Kim ME, Ha TK, Yoon JH and Lee JS: Myricetin induces cell death of human colon cancer cells via BAX/BCL2-dependent pathway. Anticancer Res 34: 701-706, 2014.

26. Zhang XH, Chen SY, Tang L, Shen YZ, Luo L, Xu CW, Liu Q and Li D: Myricetin induces apoptosis in Hepg2 cells through Akt/P70s6k/bad signaling and mitochondrial apoptotic pathway. Anticancer Agents Med Chem 13: 1575-1581, 2013.

27. Nirmala P and Ramanathan M: Effect of myricetin on 1,2 dimethylhydrazine induced rat colon carcinogenesis. J Exp Ther Oncol 9: 101-108, 2011.

28. Zhang S, Wang L, Liu H, Zhao G and Ming L: Enhancement of recombinant myricetin on the radiosensitivity of lung cancer A549 and H1299 cells. Diagn Pathol 9: 68, 2014. 
29. Wang L, Feng J, Chen X, Guo W, Du Y, Wang Y, Zang W, Zhang $S$ and Zhao G: Myricetin enhance chemosensitivity of 5-fluorouracil on esophageal carcinoma in vitro and in vivo. Cancer Cell Int 14: 71, 2014.

30. Yang D, Gao L, Wang T, Qiao Z, Liang Y and Zhang P: Hypoxia triggers endothelial endoplasmic reticulum stress and apoptosis via induction of VLDL receptor. FEBS Lett 588: 4448-4456, 2014.

31. Yamamoto S, Yamashita A, Arakaki N, NemotoH and Yamazaki T: Prevention of aberrant protein aggregation by anchoring the molecular chaperone $\alpha \mathrm{B}$-crystallin to the endoplasmic reticulum. Biochem Biophys Res Commun 455: 241-245, 2014.

32. Komatsu $M$ and Ichimura $Y$ : Physiological significance of selective degradation of p62 by autophagy. FEBS Lett 584 1374-1378, 2010.

33. Zheng YZ, Cao ZG, Hu X and Shao ZM: The endoplasmic reticulum stress markers GRP-78 and CHOP predict disease-free survival and responsiveness to chemotherapy in breast cancer. Breast Cancer Res Treat 145: 349-358, 2014.
34. Yu H, Su J, Xu Y, Kang J, Li H, Zhang L, Yi H, Xiang X, Liu F and Sun L: p62/SQSTM1 involved in cisplatin resistance in human ovarian cancer cells by clearing ubiquitinated proteins. Eur J Cancer 47: 1585-1594, 2011.

35. Yang D, Gao L, Wang T, Qiao Z, Liang Y and Zhang P: Hypoxia triggers endothelial endoplasmic reticulum stress and apoptosis via induction of VLDL receptor. FEBS Lett 588: 4448-4456, 2014.

36. Ahmad M, Hahn IF and Chatterjee S: GRP-78 up-regulation leads to hypersensitization to cisplatin in A549 lung cancer cells. Anticancer Res 34: 3493-3500, 2014.

37. Chen Z, Ballar P, Fu Y, Luo J, Du S and Fang S: The E3 ubiquitin ligase gp78 protects against ER stress in zebrafish liver. J Genet Genomics 41: 357-368, 2014.

38. Macfie A,Hagan E and Zhitkovich A: Mechanism of DNA-protein cross-linking by chromium. Chem Res Toxicol 23: 341-347, 2010.

39. Panier $S$ and Boulton SJ: Double-strand break repair: 53BP1 comes into focus. Nat Rev Mol Cell Biol 15: 7-18, 2014. 